\title{
Anomalously high thermoelectric power factor in epitaxial ScN thin films
}

Kerdsongpanya, Sit; Van Nong, Ngo; Pryds, Nini; Žukauskait, Agn; Jensen, Jens; Birch, Jens; Lu, Jun; Hultman, Lars; Wingqvist, Gunilla; Eklund, Per

Published in:

Applied Physics Letters

Link to article, DOI:

$10.1063 / 1.3665945$

Publication date:

2011

Link back to DTU Orbit

Citation (APA):

Kerdsongpanya, S., Van Nong, N., Pryds, N., Žukauskait, A., Jensen, J., Birch, J., Lu, J., Hultman, L., Wingqvist, G., \& Eklund, P. (2011). Anomalously high thermoelectric power factor in epitaxial ScN thin films. Applied Physics Letters, 99, 232113. https://doi.org/10.1063/1.3665945

\section{General rights}

Copyright and moral rights for the publications made accessible in the public portal are retained by the authors and/or other copyright owners and it is a condition of accessing publications that users recognise and abide by the legal requirements associated with these rights.

- Users may download and print one copy of any publication from the public portal for the purpose of private study or research.

- You may not further distribute the material or use it for any profit-making activity or commercial gain

- You may freely distribute the URL identifying the publication in the public portal

If you believe that this document breaches copyright please contact us providing details, and we will remove access to the work immediately and investigate your claim. 

microscopy

23

24

* Corresponding author. E-mail sitke@ifm.liu.se (IFM), Linköping University, SE-581 83 Linköping, Sweden.

\section{ABSTRACT} transition-metal nitrides.

\section{Anomalously high thermoelectric power factor in epitaxial ScN thin films}

Sit Kerdsongpanya* ${ }^{\mathrm{a}}$, Ngo Van Nong ${ }^{\mathrm{b}}$, Nini Pryds ${ }^{\mathrm{b}}$, Agnė Žukauskaite ${ }^{\mathrm{a}}$, Jens Jensen ${ }^{\mathrm{a}}$, Jens Birch $^{\mathrm{a}}$, Jun Lu ${ }^{\mathrm{a}}$, Lars Hultman, ${ }^{\mathrm{a}}$ Gunilla Wingqvist ${ }^{\mathrm{a}}$, Per Eklund ${ }^{\mathrm{a}}$

${ }^{a}$ Thin Film Physics Division, Department of Physics, Chemistry, and Biology

${ }^{\mathrm{b}}$ Fuel Cells \& Solid State Chemistry Division, Risø National Laboratory for Sustainable Energy, Technical University of Denmark, DK-4000 Roskilde, Denmark.

Thermoelectric properties of ScN thin films grown by reactive magnetron sputtering on $\mathrm{Al}_{2} \mathrm{O}_{3}(0001)$ wafers are reported. X-ray diffraction and elastic recoil detection analyses show that the composition of the films is close to stoichiometry with trace amounts $(\sim 1$ at.\% in total) of $\mathrm{C}$, O, and $\mathrm{F}$. We found that the $\mathrm{ScN}$ thin-film exhibits a rather low electrical resistivity of $\sim 2.94 \mu \Omega \cdot \mathrm{m}$, while its Seebeck coefficient is approximately $-86 \mu \mathrm{V} / \mathrm{K}$ at $800 \mathrm{~K}$, yielding a power factor of $\sim 2.5 \times 10^{-3} \mathrm{~W} / \mathrm{m} \cdot \mathrm{K}^{2}$. This value is anomalously high for common

Keywords: Transition-metal nitride, Seebeck coefficient, X-ray diffraction, Electron 
Thermoelectric generators using thermoelectric materials directly convert heat into electricity by generating a potential difference in response to a temperature gradient (or vice versa). The conversion efficiency of a thermoelectric device depends on the thermoelectric figure of merit (ZT) at a certain temperature (T), where $Z=S^{2} /(\rho \cdot \kappa)$ and $S, \rho$, and $\kappa$ are the Seebeck coefficient, the electrical resistivity, and the thermal conductivity, respectively. Since S, $\rho$, and $\kappa$ are interdependent, it is a challenging task to improve ZT. ${ }^{1,2}$ For typical thermoelectric materials, $\kappa$ is dominated by the lattice thermal conductivity; the maximum $\mathrm{ZT}$ is then close the maximum of the parameter $S^{2} / \rho$, called the power factor. Here, we report a thermoelectric power factor of $2.5 \times 10^{-3} \mathrm{~W} /\left(\mathrm{m} \cdot \mathrm{K}^{2}\right)$ at $800 \mathrm{~K}$ for epitaxial ScN thin films due to a relatively high Seebeck coefficient of $\sim-86 \mu \mathrm{V} / \mathrm{K}$ with low electrical resistivity $(\sim 2.94 \mu \Omega \cdot \mathrm{m})$. This is an anomalously high power factor for transition-metal nitrides and may place ScN-based materials as promising candidates for high temperature thermoelectric applications.

Transition-metal nitrides have not been commonly considered for thermoelectric applications. Yet, they are much appreciated as wear-resistant coatings and electronic contacts materials because of their thermal and mechanical stability, electrical conductivity, and chemical inertness. Like many other transition-metal nitrides, ScN has high hardness and high melting point $\sim 2900 \mathrm{~K}^{3,4}$ It possesses a $\mathrm{NaCl}$ (B1) crystal structure with a lattice parameter of 4.521 Å. For electrical properties, theoretical studies reported that $\mathrm{ScN}$ is an indirect semiconductor with energy gap in the range of 0.9-1.6 eV..$^{5-9}$ Measurements on as-deposited ScN show ntype behavior ${ }^{10,11}$ and the carrier concentration of $\mathrm{ScN}$ has been reported to vary from $10^{18}$ to $10^{22} \mathrm{~cm}^{-3}$ with electron mobility of $100-180 \mathrm{~cm}^{2} \mathrm{~V}^{-1} \mathrm{~s}^{-1} \cdot{ }^{9,12-14}$ These numbers of the carrier concentrations span the typical ideal range for thermoelectrics ${ }^{1}$ while retaining a high carrier mobility; ${ }^{13}$ a fact relevant to their thermoelectric power factor reported here. 
ScN films were grown onto $\mathrm{Al}_{2} \mathrm{O}_{3}(0001)$ substrates using reactive magnetron sputtering in an ultrahigh vacuum chamber with a base pressure of $\sim 10^{-7} \mathrm{~Pa}$. The chamber is described elsewhere. ${ }^{15}$ The Sc target (99.99\% purity specified as the amount of Sc divided by the total rare-earth metals in the target) has a diameter of $5 \mathrm{~cm}$. The substrates were one-side polished $\mathrm{Al}_{2} \mathrm{O}_{3}(0001)$ wafers. Prior to deposition, the substrates were degreased in an ultrasonic bath with trichloroethylene, acetone, and isopropanol for 5 min. each, and subsequently blown dry with $\mathrm{N}_{2}$. Before deposition, the substrates were heated in vacuum to the deposition temperature $800{ }^{\circ} \mathrm{C}$ (for $1 \mathrm{~h}$ for temperature stabilization and degassing). The Sc target was operated in dc mode (power-regulated) at a power of $80 \mathrm{~W}$. The substrate was rotated during deposition in order to obtain uniform films. The depositions were performed in $\mathrm{Ar} / \mathrm{N}_{2}$ (flow ratio $87 \% \mathrm{Ar} / 13 \% \mathrm{~N}_{2}$ ) with the total gas pressure at $0.2 \mathrm{~Pa}$. Structural characterization of asdeposited films was performed by X-ray diffraction (XRD) using $\mathrm{CuK}_{\alpha}$ radiation. $\theta-2 \theta$ scans were measured in a Philips PW 1820 diffractometer; $\phi$-scans and pole figures were measured in a Philips X'pert Materials Research Diffractometer operated with point focus, primary optics of $2 \times 2 \mathrm{~mm}$ cross slits, and secondary optics with parallel-plate collimator. The $\phi$-scan of ScN 200 peak was scanned with a fixed $2 \theta$ angle of $40.16^{\circ}$, a fixed tilt angle $(\psi)$ of $54.7^{\circ}$, and azimuth-angle $(\phi)$ range $0-360^{\circ}$ with step size $0.1^{\circ}$. Cross-sectional specimens for transmission electron microscopy (TEM) were prepared by gluing two pieces of the sample face to face and clamped with a Ti grid, polishing down to $50 \mu$ m thickness. Ion milling was performed in a Gatan Precision Ion Polishing System (PIPS) at $\mathrm{Ar}^{+}$energy of $5 \mathrm{kV}$ and a gun angle of $5^{\circ}$, with a final polishing step with $2 \mathrm{kV} \mathrm{Ar}^{+}$energy and angle of $2^{\circ}$. TEM characterization was performed using a Tecnai G2 TF20UT with a field-emission gun (FEG). Compositional analysis of as-deposited film was performed by time-of-flight elastic recoil detection analysis (ToF-ERDA). Here, a $30 \mathrm{MeV}^{127} \mathrm{I}^{9+}$ beam was directed to the films at an incident angle of $67.5^{\circ}$ with respect to the surface normal, and the target recoils were detected 
at an angle of $45^{\circ}$. The spectra was analyzed using the CONTES code for conversion to composition depth profile. ${ }^{16,17}$ The Seebeck coefficient and in-plane electrical resistivity of the film were simultaneously measured from room temperature up to $\sim 800 \mathrm{~K}$ by an ULVACRIKO ZEM3 system in vacuum with a low-pressure helium atmosphere. The substrate contribution to the Seebeck coefficient and electrical resistivity is negligible. Hall-effect measurements were done at room temperature in van der Pauw configuration with four symmetrical electrodes and platinum contacts bonded by gold wires to the electrodes.

Figure 1(a) shows a $\theta$ - $2 \theta$ XRD pattern from an as-deposited ScN film. The pattern shows the ScN 111 diffraction peak at a $2 \theta$ angle of $34.33^{\circ}$ corresponding very well to ICDD PDF 450978 as well as the $\mathrm{Al}_{2} \mathrm{O}_{3}(0001)$ substrate peak. From the 111 peak position of the ScN film, the lattice parameter was determined to be $4.51 \AA$. The inset of Fig. 1 shows a $\phi$-scan of ScN 200 at $40.16^{\circ}$. The six peaks are due to diffraction from planes of the $\{200\}$ family. The threefold symmetry of the [200] orientation in a cubic crystal should give three peaks; the fact that there are six shows that there are twin-domains because of different stacking sequences in which $\mathrm{ScN}(111)$ can be grown on $\mathrm{Al}_{2} \mathrm{O}_{3}(0001)$. The expected epitaxial relationship for the $\mathrm{ScN}(111)$ grown onto the $\mathrm{Al}_{2} \mathrm{O}_{3}(0001)$ surface would be $<1 \overline{1} 0>{ }_{\mathrm{ScN}} \|<10 \overline{1} 0>_{\mathrm{Al}_{2} \mathrm{O}_{3}}$ in-plane and (111) ${ }_{\mathrm{ScN}} \|(0001)_{\mathrm{Al}_{2} \mathrm{O}_{3}}$ out of plane. However, XRD shows that the $<110>$ directions of the ScN domains are here rotated in average $\pm 4^{\circ}$ compare to the $<10 \overline{1} 0>$ direction on the sapphire surface. This effect may be due to minimize the stresses resulting from the $17 \%$ positive mismatch between the $\mathrm{ScN}$ and sapphire lattices and weak interaction from second or third nearest neighbor of rhombohedral/cubic stacking.

Figure 2(a) is an overview cross-section TEM image of a typical ScN film. It can be seen that the film has columnar domains and a thickness of $\sim 180 \mathrm{~nm}$. Fig. 2(b) shows a high-resolution 4 
image of the interface area of film and substrate. The image shows the epitaxial growth of

$101 \mathrm{ScN}$ on $\mathrm{Al}_{2} \mathrm{O}_{3}$, consistent with XRD. Fig. 2(c) shows a high resolution TEM image with a

102 lattice parameter $a$ of ScN which agrees with that observed by XRD. ERDA showed that the

103 film composition is $49.6 \pm 1.5$ at.\% of Sc and $49.3 \pm 1.5$ at.\% of $N$, i.e., close to stoichiometric.

104 There are trace amounts of F, O, and C ( 0.7 at.\%, $\sim 0.3$ at.\%, and $\sim 0.1$ at.\%, respectively).

105 The source of the fluorine is from the Sc target due to the production process. The appearance

106 of the films is transparent orange, which indicates that the composition is close to 107 stoichiometric. $^{10,12}$

108

109 The thermoelectric properties of ScN are shown in Figure 3(a) and (b). At $800 \mathrm{~K}$, the Seebeck

110 coefficient is $\sim-86 \mu \mathrm{V} / \mathrm{K}$ and the in-plane electrical resistivity is $\sim 2.94 \mu \Omega \cdot \mathrm{m}$, giving a power

111 factor of $2.5 \times 10^{-3} \mathrm{~W} / \mathrm{m} \cdot \mathrm{K}^{2}$. By assuming the literature value for the thermal conductivity of

$112 \mathrm{ScN}^{4}$ the $\mathrm{ZT}$ value can be estimated to $\sim 0.2$ at $800 \mathrm{~K}$. This should be considered a lower limit

113 of ZT. Even so, it is comparable to such established thermoelectric materials as

114 polycrystalline $\mathrm{Ca}_{3} \mathrm{Co}_{4} \mathrm{O}_{9}{ }^{18}$ In comparison with other transition-metal (like $\mathrm{CrN}$ ), the $\mathrm{ScN}$ is

115 five times larger in ZT value. ${ }^{19}$ The measurements were performed in several cycles from

116 room temperature to $800 \mathrm{~K}$ to ensure the obtained results are reproducible. Fig. 3(b) shows the

117 repeated power factor measurement; the values are virtually identical. The diffraction pattern

118 of the ScN was also unchanged after three cycles from room temperature to $800 \mathrm{~K}$,

119 confirming the structural stability of the ScN films in this temperature range.

121 The results show that our ScN films have a relatively high (negative) Seebeck coefficient for

122 transition-metal nitrides in combination with a high electrical conductivity, resulting in a

123 remarkably high thermoelectric power factor. In order to tentatively explain this phenomenon,

124 we note that the conductivity is metallic-like both in magnitude and temperature-dependence. 
125 Hall measurements at room temperature yielded an electron concentration of $1.0 \times 10^{21} \mathrm{~cm}^{3}$ 126 and an electron mobility of $30.0 \mathrm{~cm}^{2} \mathrm{~V}^{-1} \mathrm{~s}^{-1}$. This may be due to small contamination from 127 oxygen, fluorine or nitrogen vacancies acting as dopants to increase carrier concentration.

128 Additionally, the impurities might cause rapidly changing features in the density of states near 129 the Fermi level. It has been theoretically predicted that nitrogen vacancies have this role in 130 ScN and it is reasonable that dopants could yield a similar effect. ${ }^{7}$ Preliminary caluclations 131 support this notion. ${ }^{20}$ Such features in the density of states would correspond to the Mahan 132 and Sofo prediction of the transport-distribution function that maximizes ZT. ${ }^{21}$

134 Additional samples (not shown) with higher oxygen contents (1-3 at.\%) and/or 135 substoichiometric in nitrogen, exhibited Seebeck coefficients somewhat lower, but of the 136 same order as shown in Fig. 3(a). However, they also exhibited large difference in electrical 137 resistivity, i.e., up to one order of magnitude higher electrical resistivity for 1-3 at.\% O 138 content than the ScN films with $\sim 0.3$ at.\% O content. Hall measurements for ScN with $\sim 1-3$ 139 at.\% O show an electron concentration increase to $1.25 \times 10^{21}-1.75 \times 10^{21} \mathrm{~cm}^{3}$ and electron 140 mobilities in the range $0.5-1.6 \mathrm{~cm}^{2} \mathrm{~V}^{-1} \mathrm{~s}^{-1}$. This may be due to either incorporation of $\mathrm{O}$ in 141 ScN or formation of secondary phases, e.g., amorphous oxides. According to the Mott 142 equation, the Seebeck coefficient is independent of mobility if the mobility is energy143 independent, therefore these data are consistent with the large reduction in conductivity (due 144 to reduced mobility) and limited reduction in Seebeck coefficient. These observations of large 145 variation in properties emphasize the importance of impurities and defects. The only previous 146 report on thermoelectric properties of ScN reported a relatively modest power factor for "bulk 147 ScN” without providing any information about the samples or their purity. ${ }^{22}$ 
In conclusion, the thermoelectric properties of epitaxial ScN thin films have been studied in

150 detail. It is possible to obtain ScN exhibiting a remarkably high power factor $2.5 \times 10^{-3}$

$151 \mathrm{~W} /\left(\mathrm{m} \cdot \mathrm{K}^{2}\right)$ at $800 \mathrm{~K}$ which corresponds to a relatively high Seebeck coefficient of $\sim-86 \mu \mathrm{V} / \mathrm{K}$

152 while retaining a rather low and metallic-like electrical resistivity $(\sim 2.94 \mu \Omega \cdot \mathrm{m})$. The

153 estimated lower limit of ZT is $\sim 0.2$ at $800 \mathrm{~K}$, which suggests that the ScN-based materials as

154 candidates for high-temperature thermoelectrics application.

155

156

ACKNOWLEDGMENT

157 Funding from the Swedish Research Council (VR, grant number 621-2009-5258) is 158 acknowledged.

159

160

REFERNCES

$161{ }^{1}$ G. J. Snyder and E. S. Toberer, Nat. Mater. 7, 105 (2008).

$162 \quad{ }^{2}$ F. J. DiSalvo, Science 285, 703 (1999).

$163{ }^{3}$ D. Gall, I. Petrov, N. Hellgren, L. Hultman, J. E. Sundgren, and J. E. Greene, J. Appl. Phys.

164 84, 6034 (1998).

$165{ }^{4}$ V. Rawat, Y. K. Koh, D. G. Cahill, and T. D. Sands, J. Appl. Phys. 105, 024909 (2009).

166 5D. Gall, M. Städele, K. Järrendahl, I. Petrov, P. Desjardins, R. T. Haasch, T.-Y. Lee, and J.

167 E. Greene, Phys. Rev. B 63, 125119 (2001).

$168{ }^{6}$ C. Stampfl, W. Mannstadt, R. Asahi, and A. J. Freeman, Phys. Rev. B 63, 155106 (2001).

$169{ }^{7}$ M. G. Moreno-Armenta and G. Soto, Computational Materials Science 40, 275 (2007).

$170 \quad{ }^{8}$ W. R. L. Lambrecht, Phys. Rev. B 62, 13538 (2000).

$171{ }^{9}$ H. A. Al-Brithen, A. R. Smith, and D. Gall, Phys. Rev. B 70, 045303 (2004).

$172{ }^{10}$ H. A. H. Al-Brithen, E. M. Trifan, D. C. Ingram, A. R. Smith, and D. Gall, J. Cryst. Growth 173242,345 (2002). 
${ }^{11}$ M. A. Moram, Z. H. Barber, and C. J. Humphreys, Thin Solid Films 516, 8569 (2008).

$175{ }^{12}$ G. Travaglini, F. Marabelli, R. Monnier, E. Kaldis, and P. Wachter, Phys. Rev. B 34, 3876 176 (1986).

$177{ }^{13}$ J. M. Gregoire, S. D. Kirby, G. E. Scopelianos, F. H. Lee, and R. B. van Dover, J. Appl. 178 Phys. 104, 074913 (2008).

$179{ }^{14}$ J. P. Dismukes, W. M. Yim, J. J. Tietjen, and R. E. Novak, R.C.A. Review 31, 680 (1970).

$180{ }^{15}$ D. H. Trinh, H. Hogberg, J. M. Andersson, M. Collin, I. Reineck, U. Helmersson, and L. 181 Hultman, J. Vac. Sci. Technol. A. 24, 309 (2006).

$182{ }^{16}$ M. S. Janson, CONTES, Conversion of Time-Energy Spectra A Program for ERDA Data 183 Analysis, Internal Report, Uppsala University, 2004.

$184{ }^{17}$ H. J. Whitlow, G. Possnert, and C. S. Petersson, Nucl. Instrum. Meth. B 27, 448 (1987).

$185 \quad{ }^{18}$ N. V. Nong, N. Pryds, S. Linderoth, and M. Ohtaki, Adv. Mater. 23, 2484 (2011).

$186{ }^{19}$ C. X. Quintela, F. Rivadulla, and J. Rivas, Appl. Phys. Lett. 94, 152103 (2009).

$187{ }^{20}$ G. Soto, M. G. Moreno-Armenta, and A. Reyes-Serrato, arXiv:0803.3644v1[cond-mat.mtr]188 sci], epublished (2008).

$189{ }^{21}$ G. D. Mahan and J. O. Sofo, Proc. Nat. Acad. Sci. USA 93, 4436 (1996).

$190 \quad{ }^{22}$ M. Zebarjadi, Z. Bian, R. Singh, A. Shakouri, R. Wortman, V. Rawat, and T. Sands, J. 191 Electron. Mater. 38, 960 (2009).

192 


\section{FIGURE CAPTIONS}

194 FIG 1. $\theta-2 \theta$ x-ray diffraction pattern from a ScN film deposited onto an $\mathrm{Al}_{2} \mathrm{O}_{3}(0001)$ 195 substrate. The inset shows a $\phi$-scan plot of (solid line) the ScN 200 plane and (dot line) the $196 \mathrm{Al}_{2} \mathrm{O}_{3} 10 \overline{1} 4$ plane.

197

198 FIG 2. Cross-sectional TEM micrographs of a $\mathrm{ScN}$ film on $\mathrm{Al}_{2} \mathrm{O}_{3}(0001)$ substrate in (a) 199 overview and (b) high resolution of the film/substrate interface, and (c) high-resolution of a 200 region in the bulk of the film.

201

202 FIG 3. (color online) Thermoelectric properties of a ScN film was measured from room 203 temperature to $800 \mathrm{~K}$, (a) Seebeck coefficient (left) and electrical resistivity (right) as 204 functions of temperature, and (b) Power factor $S^{2} / \rho$ vs. temperature from $300-800 \mathrm{~K}$ for 205 three measured cycles.

206 


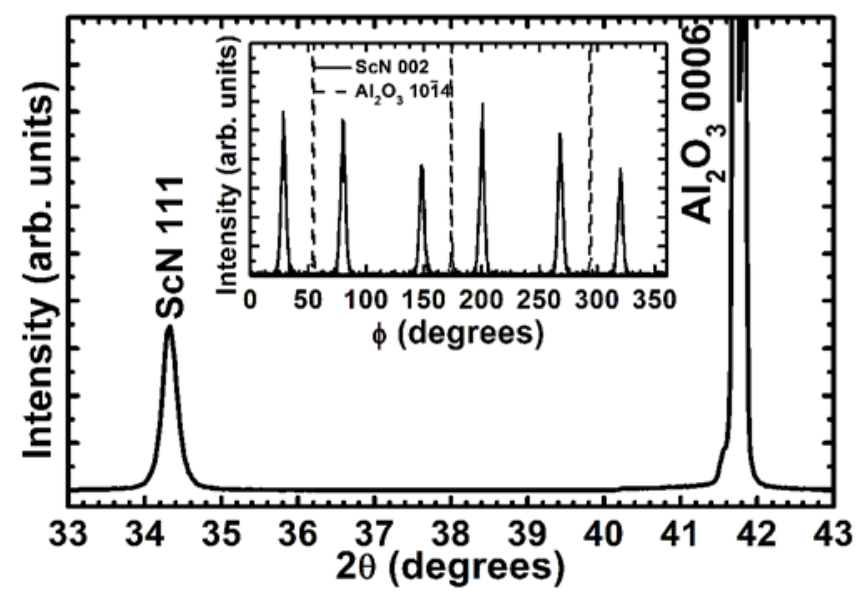




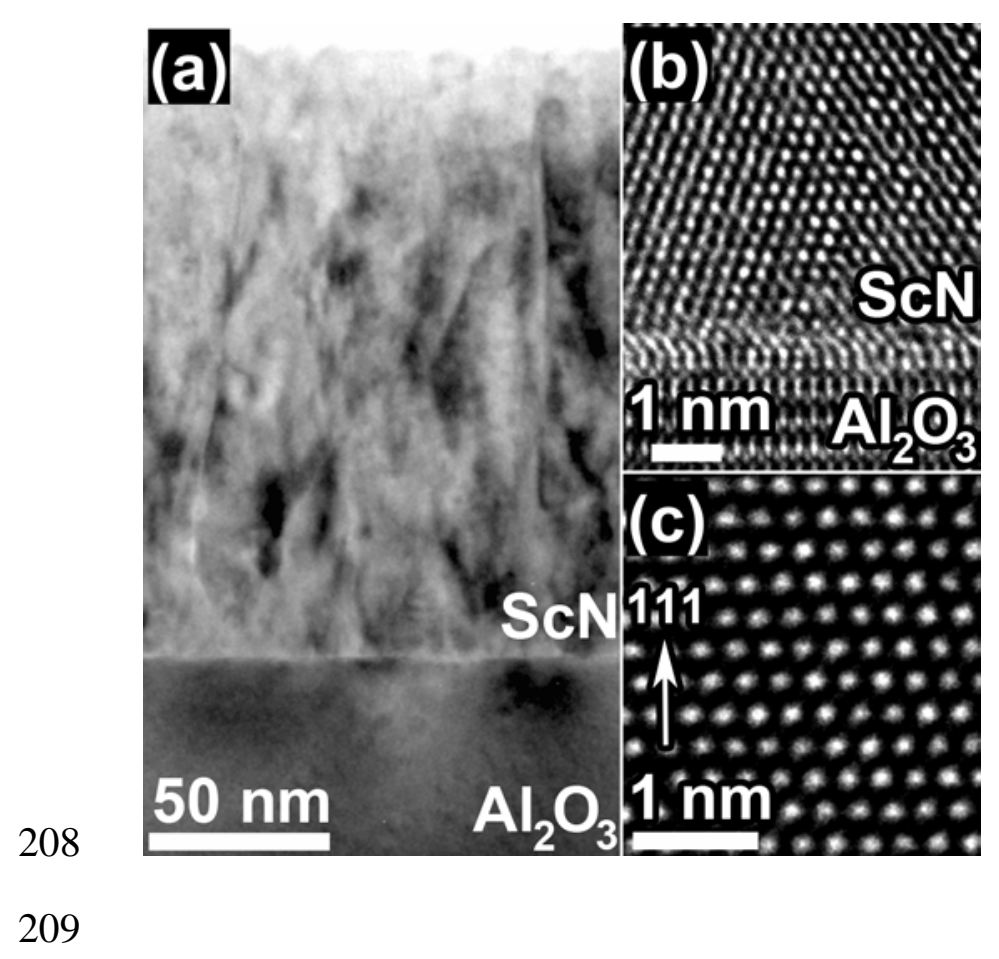




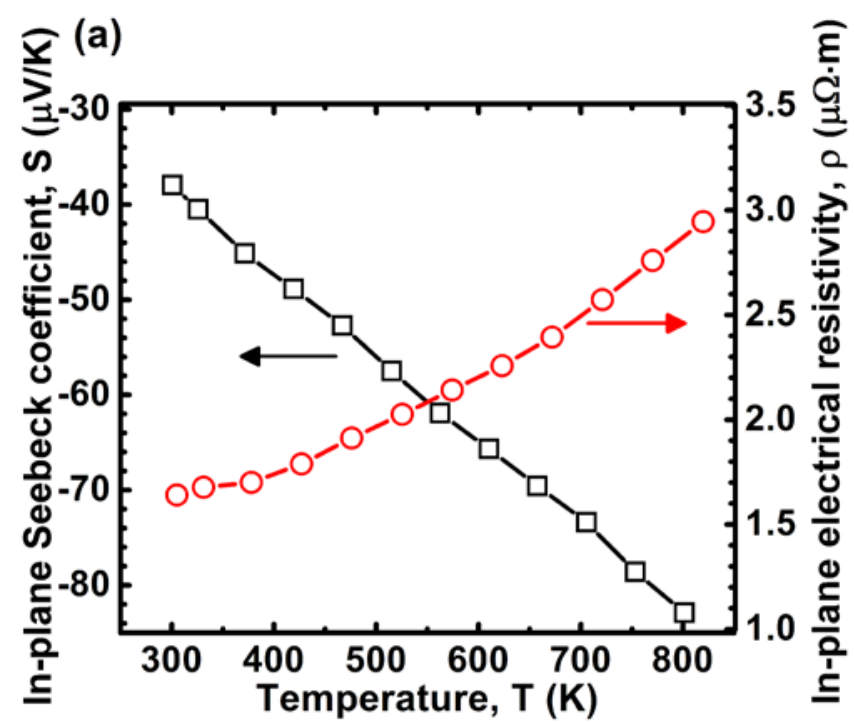

(b)

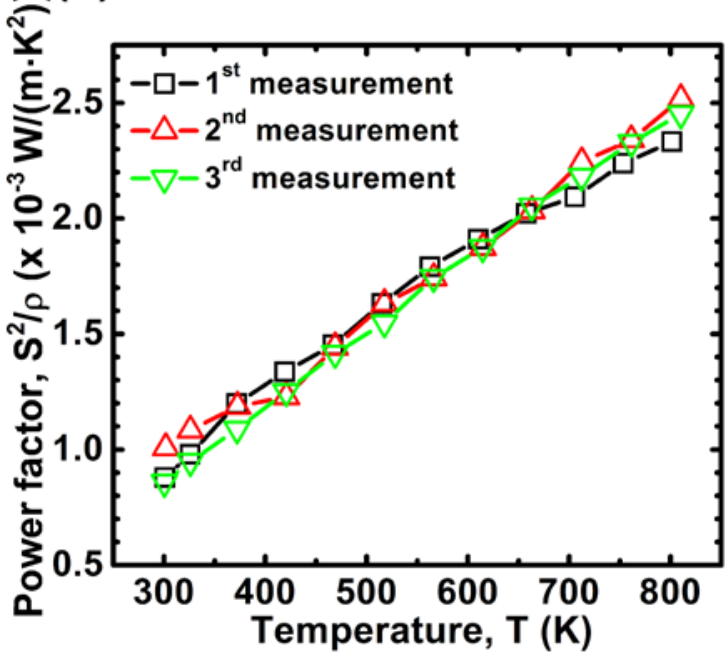

